\title{
Inventorying slope movements in an Alpine environment using DInSAR
}

\author{
Chloé Barboux, ${ }^{1 *}$ Reynald Delaloye $^{1}$ and Christophe Lambiel ${ }^{2}$ \\ ${ }^{1}$ University of Fribourg, Department of Geosciences, Geography, Chemin du Musée 4, Fribourg 1700 Switzerland \\ ${ }^{2}$ Institute of Earth Surface Dynamics, University of Lausanne, Géopolis, 1015 Lausanne, Switzerland
}

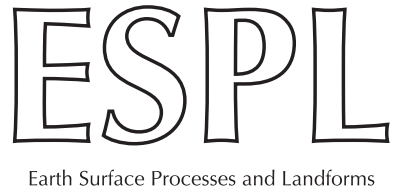

\begin{abstract}
Differential SAR Interferometry (DInSAR) is a technique that can be used to detect and characterize slope movements. It is investigated here as a tool for establishing a detailed overview of complex slope movements at a regional scale in an Alpine context. This paper gives specific recommendations to use and to understand DInSAR signals in mountainous areas located above the tree line, excluding glaciated areas. It proposes a systematic procedure based on accurate interpretations of interferometric signals from a large DInSAR dataset to locate and estimate the displacement rate of moving zones. The methodology was successfully applied in the Western Swiss Alps, where about 1500 moving objects were detected above the tree line using a large dataset of ERS and JERS interferograms dating from the 1990s. The DInSAR-detected movements had a displacement rate ranging from a few centimeters to several meters per year and were attributed to various types of mass wasting phenomena (rock glaciers, landslides, etc.). This kind of inventory derived from DInSAR can be used as a preliminary tool for natural hazard management and process understanding in mountain areas. As automatic data archiving and systematic acquisition of SAR data are ensured worldwide for most SAR sensors, a similar methodology can basically be applied in many other parts of the globe - also by using data from current SAR sensors - as long as a high resolution DEM is available. Copyright @ 2014 John Wiley \& Sons, Ltd.
\end{abstract}

KEYWORDS: DInSAR; inventory; slope movement; landslide; rock glacier

\section{Introduction}

Differential synthetic aperture radar interferometry (DInSAR) serves to detect small temporal variations of the Earth surface topography that occur in the satellite line of sight (LOS) in the order of a few centimeters or even less and provide accurate kinematical data of various geophysical phenomena related, for instance, to tectonic and volcanic activities, land subsidence, ice sheet and glacier movement, and landslides (Gabriel et al., 1989; Bamler and Hartl, 1998; Massonnet and Feigl, 1998; Rosen et al., 2000). Since the launch of ERS-1 in July 1991 by the European Space Agency (ESA) a large set of available interferometric data has been archived. The use of DInSAR has been rapidly well established.

Two-pass DInSAR is one of the most common methods in differential satellite-based interferometry and provides data with extensive spatial coverage allowing the simultaneous investigation of many phenomena at the regional scale. This extensive coverage is difficult to obtain with classical geodetic techniques. This approach consists of co-analyzing the phase difference between two SAR images from two separate flight tracks and removing the topographic contribution using a digital elevation model (DEM). In the framework of several projects carried out over the last decade (Delaloye et al., 2007a, 2007b, 2008, 2010b; Lambiel et al., 2008; Barboux et al., 2013a), large inventories of Alpine slope movements have been taken in various regions of the Swiss Alps using 2-pass DInSAR to assess both the surface geometry and the activity of detected landforms. They may be related to glaciers and particularly to debris-covered (parts of) glaciers as well as to the creep of frozen debris (rock glaciers, push-moraines) or to landslides. Specific studies have been reported on rock glacier inventories using DInSAR in the French Alps (Echelard et al., 2013), in Sierra Nevada, California (Liu et al., 2013) as well as in Northern Iceland (Lilleøren et al., 2013). However, the potential of DInSAR has not always been fully investigated in term of data selection (Echelard et al. (2013) only used the descending mode, Liu et al. (2013) did not use ERS-1/2 tandem) or partial use of data (Lilleøren et al. (2013) only used DInSAR on a subset of rock glaciers previously mapped from aerial imagery to validate their state of activity).

This paper aims to relate experiences we gained in using 2-pass DInSAR data for geomorphological studies in mountainous environments, here the European Alps. First, it provides a comprehensive review of strengths and weaknesses (limitations) of DInSAR for slope movement detection in mountain areas. Then, a methodology is presented to inventory slope movements based on DInSAR signal interpretation and is limited to the detection and characterization of surface processes at a regional scale. A typical application will be 
given in the Western Swiss Alps, where about 1500 moving objects were detected. Finally, the proposed methodology will be discussed.

\section{Suitability of DInSAR for Characterizing Slope Movement in Alpine Environment}

\section{Generalities}

The suitability of DInSAR for application in an Alpine environment is discussed in many studies that have assessed the capability of DInSAR for analyzing slope movements (Strozzi et al., 2002, 2005; Delacourt et al., 2007) and paying regard to the large number of requirements to select, analyze and interpret DInSAR correctly in this specific topographical context (Nagler et al., 2001, 2002; Strozzi et al., 2004; Delaloye et al., 2007a, 2007b; Lambiel et al., 2008). A successful use of DInSAR is dependent on a combination of design and environmental parameters (Hanssen, 2005): mainly the imaging geometry, the radar wavelength, the perpendicular baseline (effective distance in between the satellite tracks), the temporal baseline (time interval between the image acquisitions), the atmosphere, the topography, the surface roughness (surface slope, geometry of the vegetation), the deformation characteristics (variation of surface height) as well as the surface materials (soil moisture, snow). Different combinations of these parameters may cause changes in the phase or may affect the interferogram by making the radar images locally or fully incoherent to each other. The quality of the interferogram can be estimated by means of the local correlation (cross-correlation coefficient of the SAR image pair calculated over a small window) and gives the degree of coherence measuring the phase noise in the interferogram. The coherence is lost when the scattering of the imaged surface changes in the time interval, causing temporal decorrelation. Whereas the effects related to system and geometry are well understood, the others are important to characterize so as not to misinterpret DInSAR signals (Klees and Massonnet, 1999).

\section{Imaging geometry}

Several areas are missing information due to terrain and SAR imaging geometry (Figure 1). A foreshortening effect (a)-(d) can arise if the imaged terrain surface slopes towards the radar (A)-(D) such that it appears shortened: the signal is compressed

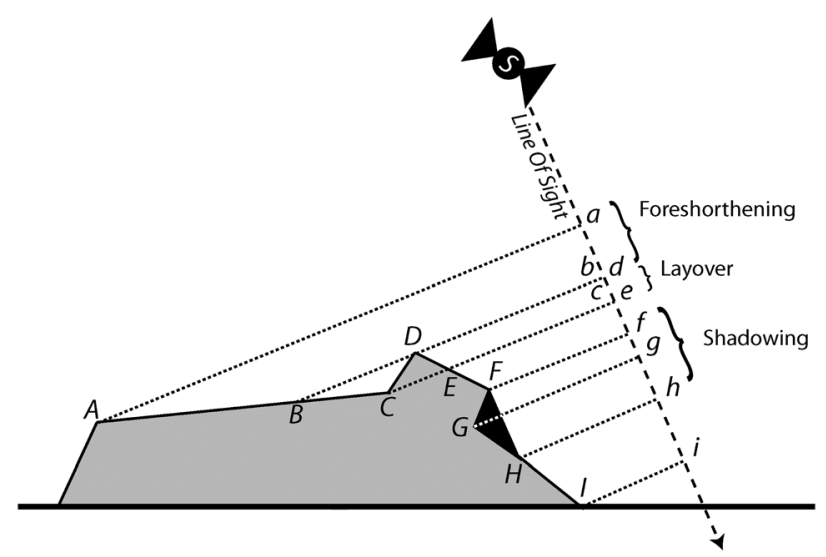

Figure 1. SAR acquisition geometry in the plane perpendicular to the orbit. and the ground resolution can be severely reduced. Layover (d)-(c) is an extreme form of foreshortening in which the top of a reflecting object, such as a mountain, is closer to the radar (in slant range) than the lower parts of the object. It can affect a larger part of the ground, namely the portions (B)-(C) and (D)-(E), and are 'passive layover', whereas (C)-(D) corresponds to the 'true layover'. The shadowing $(\mathrm{f})-(\mathrm{h})$ indicates the portion of the ground $(\mathrm{F})-(\mathrm{H})$ which is not illuminated by the radar and located in the shade created by the obstacle $(F)-(G)$. $(F)-(H)$ can be identified as two separate effects: the 'true shadow' $(\mathrm{F})-(\mathrm{G})$, where the slope is such that the radar does not see the surface (it looks at the surface from below) and the 'shadow' $(\mathrm{G})-(\mathrm{H})$ where there is an obstacle in the way of LOS, so the surface cannot be mapped by the radar.

Current SAR satellites are polar orbiting so the LOS is roughly East or West and has an impact on which slopes are suited in mountainous terrain. North and South facing slopes, where deformations are often directed in the plane perpendicular to the LOS, can be difficult to analyze. Back-facing slopes (D-I), defined as the western slope when viewing in descending mode or the eastern slope in ascending mode, are the most appropriate configuration (Rott et al., 1999; Rott et al., 2003; Strozzi et al., 2004): the local spatial resolution is less affected by geometric distortions and deformations are more or less directed in the LOS. The facing slopes (A-D) are the opposite and are less favorable for a DInSAR analysis. In addition, the slope steepness, along with the SAR incidence angle is directed, has to be considered. A steep incidence angle (for instance $23^{\circ}$ of ERS) reduces shadow effects observed in back facing slopes. Incidence angle larger than slope angle increases the shadow effect in back facing slopes and decreases layover effect in facing slopes. Consequently a good compromise has to be chosen to observe correctly the two sides of the valley in mountainous terrain. Finally, knowing incidence angle and LOS direction, the areas affected by imaging geometry are easily mapped using standard SAR software.

\section{DEM errors}

Spatial decorrelation arises due to differences in the acquisition geometry of two SAR images, leading to difficulties matching them during the registering phase. A large spatial baseline between acquisitions may cause disparities between resulting SAR images, especially in complex mountainous regions. When the spatial baseline increases, the parallax introduces additional cycles to the interferogram related to surface topography. The altitude of ambiguity $h_{a}$ is defined as the shift in altitude required to produce one topographic fringe (Massonnet and Feigl, 1998) and is inversely proportional to the spatial baseline. Thus, the effect of topography is dependent on the perpendicular baseline of the computed interferogram.

As 2-pass DInSAR uses a simulated topographic phase generated from an external digital elevation model (DEM) to eliminate the topographic contribution in the final interferogram (Wegmüller and Strozzi, 1998), the feasibility of DInSAR in detecting and quantifying deformation is limited by the quality of this DEM in term of resolution and vertical accuracy. If the DEM contains errors, the resulting interferogram will contain artificial fringes. As they appear in the same location in every interferogram using that DEM, the misinterpretation can be avoided with a large number of available interferograms (Massonnet and Feigl, 1998). To prevent artefacts, either an accurate DEM has to be used to remove the topography component correctly or image pairs with short spatial baselines should be chosen (Klees and Massonnet, 1999; Walter and Busch, 2012). 


\section{Characteristics of the surface changes}

The phase difference provides only the LOS component of the 3D surface displacement vector. Thus, the change of color in the resulting interferogram expresses the ground deformation projected into the LOS direction (Figure 2) and the resulting

\section{Near (Uplift) \\ Far (Subsidence)

$\begin{array}{lr}-\pi & +\pi \\ -\lambda / 4 \mathrm{~cm} & +\lambda / 4 \mathrm{~cm}\end{array}$ \\ LOS deformation rate $(\mathrm{cm})$}

Figure 2. The difference in deformation rate between places having the same color is a multiple of $\lambda / 2$. When the color turns from pink to yellow, the ground moves far from the satellite. In the opposite direction, the ground moves near the satellite. fringe is equivalent to a change in the LOS direction between an object imaged by the first and by the second SAR antenna of half a wavelength (Massonnet and Feigl, 1998). The direction of the change can be interpreted using the key in Figure 2. Positive phase value direction means that the radar beam has travelled further in the second acquisition and thus corresponds to a subsidence. In the opposite case, it will be interpreted as uplift. To decompose the measured motion into the vertical and horizontal components (i.e. easting and northing) it is necessary to combine ascending and descending views of the same motion. If only one acquisition mode is available, the vertical and horizontal components can be computed only if external information, such as GPS data, modelling or assumptions about the expected motion are available (Duro et al., 2013).

The rate of terrain movement that can be detected depends among others on the time interval and on the wavelength (Figure 3). The interferometric SAR signal will decorrelate when
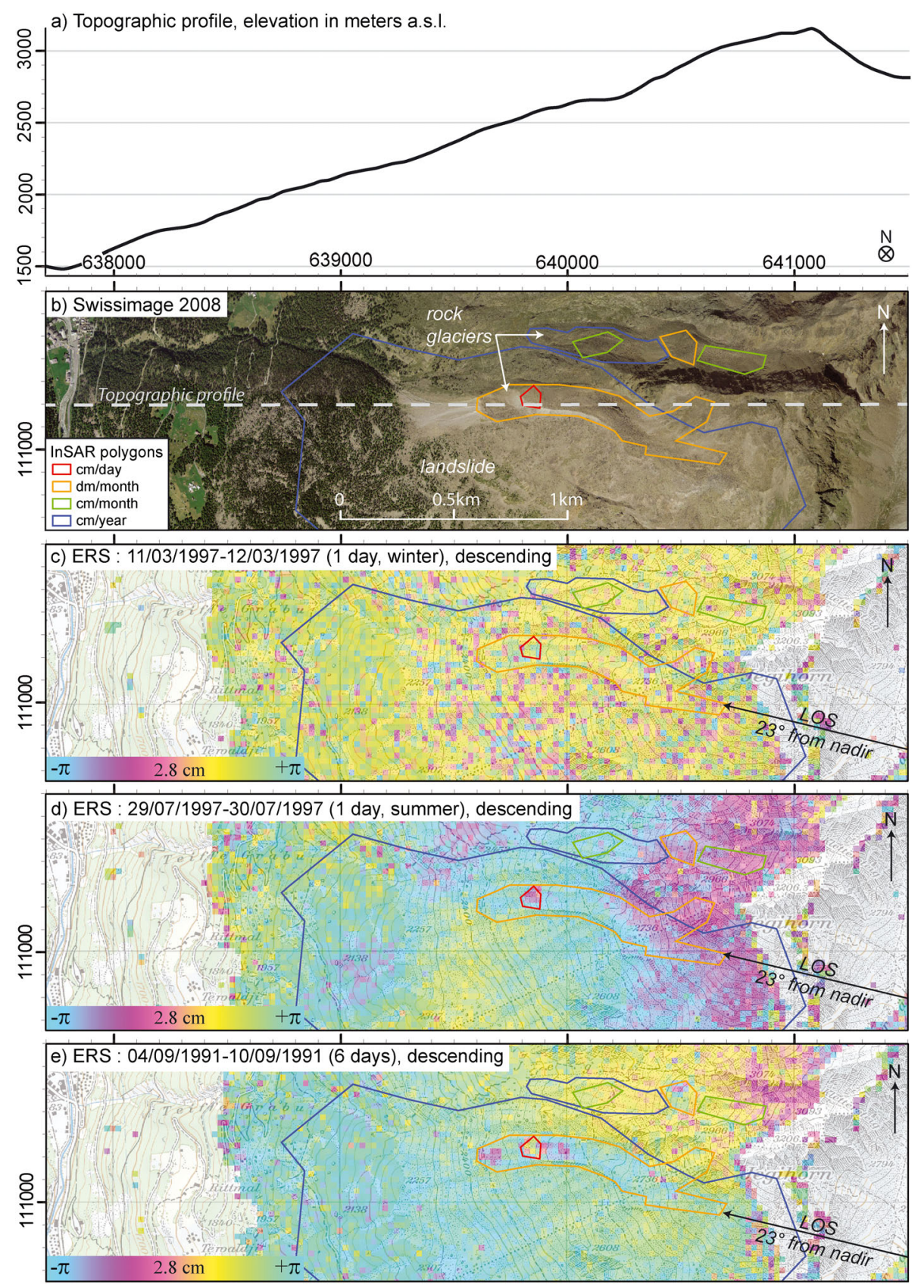

Figure 3. Saas Valley (Western Swiss Alps) (a) Topographic profile, (b) Orthoimage. Interferograms of the area using ERS (c)-(g) and TSX (h)-(j) data where layover and shadowing are masked (transparent). 


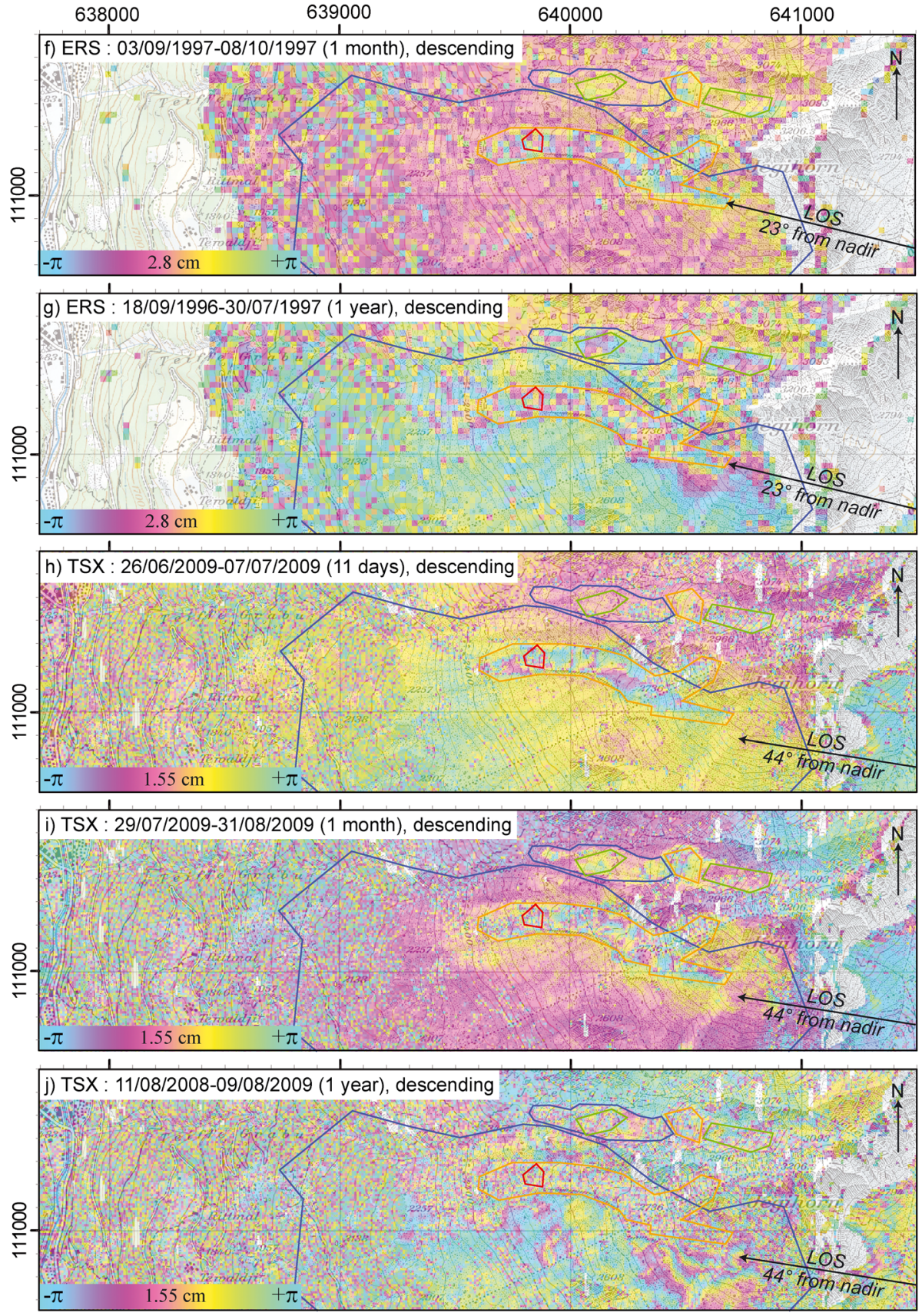

Figure 3. (Continued)

the displacement gradient between adjacent pixels is higher than half the wavelength during the selected time interval (Massonnet and Feigl, 1998). This means that the decorrelation occurrence is favored by the roughness of the surface and the displacement rate. The time interval over which the displacement is measured must be matched to the observed surface deformation (Rosen et al., 2000).

Finally, the nature of the change within a pixel can introduce noise in the measuring phase difference (Klees and Massonnet, 1999). The information on the deformation is coherent only if the entire surface within the pixel deforms homogeneously. Whereas coherent DInSAR signals can be obtained on large non-crevassed parts of glaciers despite a high displacement rate (as long as the surface is not wet), decorrelation tends to occur at lower velocity on rock glaciers due to the roughness of the surface and the smaller size of the landform. In the 1990s, the 3-day repeat cycle of ERS-1 and the 1-day ERS-1/2 tandem mission (C-band) offered a unique opportunity to observe changes over a very short interval of time.

\section{Soil moisture}

After a rainfall, it may take several days for soil to lose moisture through evaporation. With clear nights especially, dew can be expected every morning for the next few days. It is established that the dielectric property of soils (namely the permittivity, which is largely controlled by soil moisture), controls the penetration depth of microwaves (Ulaby et al., 1981). Thus, the increase of moisture and the heterogeneity in soil moisture patterns due to rainfall, for instance, can contribute to a loss of coherence (Zhang et al., 2008). However, it is still difficult to define soil moisture variations as the only source of decorrelation. Indeed, several studies mention that a change in penetration depth (related to soil moisture variations) is not necessarily the cause of decorrelation and show that when surface roughness is not altered a change in soil moisture is often associated with a simple phase shift (Massonnet and Feigl, 1998; Smith, 2002; Nolan and Fatland, 2003). In practice, we see that heavy rain events in Alpine environments (when they 
occur up to 2 days before the acquisition) may partially decorrelate the signal. As almost all of the weather events such as fog, cloud, dew, frost, etc., occur in the troposphere layer, the reason for this observed noise may also be explained by a tropospheric effect affecting the interferometric correlation (effects caused by the atmosphere are described later). Consequently, it is required to take weather conditions into consideration when interpreting DInSAR images.

\section{Snow}

In high mountains the presence of snow and its temporal changes have significant influence on the signal coherence. In wintertime, using a 1-day time interval, the snow cover is kept cold and most of the illuminated area is well visible. Dry snow preserves stable scattering geometry allowing high degrees of coherence (Strozzi et al., 1999). Some pixels could remain noisy, probably due to wet snow (Figure 3(c)). However, with a longer time interval, or when the snow surface is already melting, DInSAR interferograms are unusable due to the change of the scattering geometry (Strozzi et al., 1999). Actually, wet onset over the snow surface is commonly associated with a sharp decrease in radar backscatter intensity and wet snow cover dramatically reduces correlation (Strozzi et al., 1999; Smith, 2002).

In summer, the snow-free period may strongly vary from year to year as well as from the location of the studied area, and may be delayed or advanced by several weeks (Delaloye et al., 2007a). Late-lying snow cover, as well as avalanche cones, also result in a typical decorrelated DInSAR-signal and may subsist during the whole summer season. Moreover, snowfall in summer and autumn may happen and does not preserve correlation (Smith, 2002).

\section{Vegetation}

The vegetation canopy forms a complex and heterogeneous volume composed of leaves, stems, branches, and trunks; and disturbs the reflection of the radar wave (Figure 3). Temporal decorrelation is caused by changes in the scatterers (growth or loss of foliage, wind motion) and/or changes in the dielectric constant in between the two satellite acquisitions (Balzter, 2001).

Forest canopies are usually modeled as a volume composed of random idealized identical objects (Jones and Vaughan, 2010). The wavelength $\lambda$ of the sensor determines the penetration depth of the transmitted signal into the vegetation layer. Volume scattering is larger for shorter wavelength whereas the penetration layer is deeper for longer wavelengths (Balzter, 2001; Jones and Vaughan, 2010). The L-Band wavelength is much larger than a typical tree leaf thus certain vegetation types are transparent to the sensor and the signal penetrates through the upper vegetation layer and reflects from the soil surface (Balzter, 2001; Barrett et al., 2009; Jones and Vaughan, 2010). The short wavelength of the X-band sensor is mainly reflected at the top layer of the canopies (due to the presence of small objects, i.e. the tree leaves), disturbing the signal much more and causing a loss of coherence (Barrett et al., 2009). The behavior at C-band is less predictable. As only sparse grasses generally cover an Alpine terrain, it is especially suitable for DInSAR application.

\section{Atmosphere}

Atmospheric effects, producing a systematic error in surface displacement estimated from DInSAR, are assumed to be one of the main limiting factors for DInSAR (Klees and Massonnet, 1999). The different refraction index of the atmosphere disturbances causes pixel misregistration and artefacts in the phase difference (Tarayre and Massonnet, 1996; Zebker et al., 1997). In mountainous regions, a homogeneous tropospheric delay can affect the entire image, where color shading is visible from the bottom of the valley to the top (Figure 3(d)). As this delay is inversely dependent on the altitude of the terrain, it can be removed by adequate processing (Williams et al., 1998). Additional tropospheric turbulences, due to the time and space variations of the vapor content, induce local heterogeneous atmospheric effects difficult to interpret (Tarayre and Massonnet, 1996). The ionosphere can also perturb the signal but less severely than the troposphere. Path delay can occur in the ionosphere due to the variations in the Total Electron Content influencing the whole scene rather homogeneously or due to Travelling lonospheric Disturbances causing sometimes localized artifacts (Klees and Massonnet, 1999).

\section{Methodology for Systematic Detection of Slope Movements in Alpine Environments}

\section{Data selection and processing}

Different SAR sensors can be selected according to their availability and accessibility (Table I). To get a complete overview of slope movements in a given area and to prevent misinterpretation of detected mass wasting phenomena, it is essential to

Table I. Radar characteristics of the most commonly used SAR systems

\begin{tabular}{|c|c|c|c|c|c|c|c|c|}
\hline Satellite & Terrasar- $X$ & COSMO-SkyMed & ERS & Envisat & Radarsat1 & Radarsat2 & Alos & JERS \\
\hline Date & from 2007 & from $2007^{b}$ & $\begin{array}{l}1: 1991-2000 \\
2: 1995-2011\end{array}$ & $2002-2012$ & 1995-2011 & from 2007 & 2006-2011 & 1992-1998 \\
\hline Agency & DLR & ASI & ESA & ESA & CSA & CSA & JAXA & JAXA \\
\hline Wavelength (cm) & 3.1 & 3.1 & 5.6 & 5.6 & 5.6 & 5.6 & 23.6 & 23.6 \\
\hline Band & $X$ & $x$ & $\mathrm{C}$ & $\mathrm{C}$ & $\mathrm{C}$ & $\mathrm{C}$ & $L$ & $\mathrm{~L}$ \\
\hline Incidence angle $\left(^{\circ}\right)$ & $15-60$ & $20-60$ & 23 & $15-45$ & $20-50$ & $10-60$ & $8-60$ & 35 \\
\hline Range resolution $(\mathrm{m})^{\mathrm{a}}$ & $1-16$ & $1-100$ & 26 & $30-150$ & $10-100$ & $3-100$ & $7-100$ & 18 \\
\hline Azimuth resolution $(m)^{a}$ & $1-16$ & $1-3-100$ & 28 & $30-150$ & 9-100 & $3-100$ & $7-100$ & 18 \\
\hline Scene width (km) & $10-100$ & $10-200$ & 100 & $100-400$ & $45-500$ & $50-500$ & $40-350$ & 75 \\
\hline Repeat cycle (day) & 11 & $1-4-8-16$ & $(1-3)-35^{c}$ & 35 & 24 & 24 & 46 & 44 \\
\hline
\end{tabular}

${ }^{\mathrm{a}}$ Resolution in range and azimuth depends on the image acquisition mode. Common modes are the spotlight mode (extra precise), stripmap/standard mode and Wide/ScanSAR mode (extended).

${ }^{b}$ COnstellation of small Satellites for Mediterranean basin Observation (1st and 2nd satellites launched in 2007, 3rd in 2008 and 4th in 2010).

${ }^{\mathrm{C}}$ Three days with ERS-1 in 1991, one day with tandem ERS-1/2 from 1995. 
dispose of a large set of workable interferograms produced with various time intervals (e.g. daily, monthly and yearly) and a small spatial baseline. The major obstacle limiting a successful use of DInSAR in an Alpine environment is the presence of (wet) snow. Usable SAR scenes must be, as much as possible, snow free, which is usually between June and October in the Alps. SAR scenes with a short (daily) time interval can also be used in the wintertime, when the snow is still cold.

After SAR image selection, DInSAR interferograms should be processed in a 2-pass approach applying standard processing steps (coregistration, interferogram generation, flat Earth removal, baseline correction, topographic phase estimation using external DEM, subtraction of the estimated topographic phase). In a mountain region, the DEM used for topographic phase correction should have a minimum of $25 \mathrm{~m}$ resolution and 3-5 $\mathrm{m}$ height accuracy when working with ERS DInSAR data having a spatial baseline lower than $250 \mathrm{~m}$. With the same DEM quality and TSX data, the baseline has to be set lower (Walter and Busch, 2012). The resulting interferometric products can be multilooked in order to approximately obtain squared pixels. The process of multi-looking consists in averaging phase and coherence values at neighboring pixels comprised within a window of fixed size. An atmospheric phase model based on a linear regression of atmospheric phase with respect to the DEM can also be applied. If no final spatial filtering is applied, phase noise and residual phase error terms must not be neglected when interpreting the interferogram. Moreover, estimating the occurrence of old or fresh snow and the weather conditions (rainy event) at or up to 2 days before each SAR image date on the basis of available meteorological data has proven to be a helpful step in evaluating the quality of an interferogram (Delaloye et al., 2007a).

Before proceeding to the detection of slope movements, it is necessary to build a GIS project in which the analysis will be performed, including DInSAR data, orthoimages, topographic maps, background maps derived from a numerical terrain model, and any other kind of georeferenced data that could help in the interpretation of DInSAR signals (Figure 4).

\section{Procedure for slope movement inventory}

The present methodology aims (i) to identify moving landforms over a large region, (ii) to spatially outline areas with an almost homogeneous deformation rate (hereafter called DInSAR

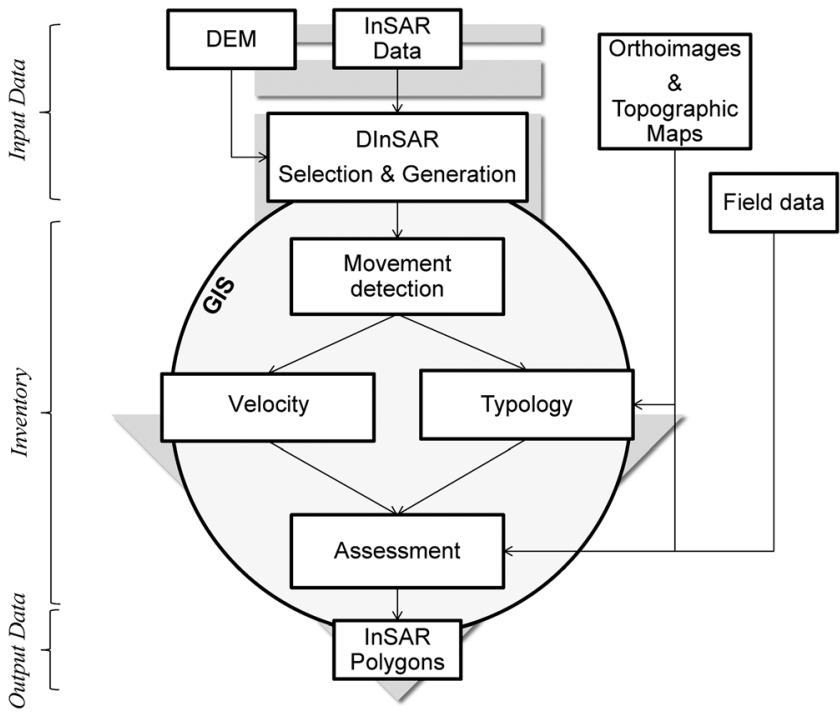

Figure 4. Procedure for the proposed inventory of slope movements in Alpine periglacial environments using DInSAR data. The analysis is performed in GIS software. polygons), and (iii) to categorize the deformation rate of the detected DInSAR polygons by assessing qualitatively the DInSAR signals that can be observed on interferograms with different time intervals (Delaloye et al., 2007a). A detected moving landform is indicated using polygons which are manually drawn. They describe an area where a given DInSAR signal is detected and do not necessarily fit the morphological outline of the landform.

The detection is performed by looking for a fringe pattern and/or noise on an interferogram, which means looking at a single pixel according to its neighbors together. The minimal size of detectable targets is consequently limited by the spatial resolution of the interferogram as well as by the filtering applied to reduce noise. The estimation of the deformation rate is performed by comparing the phase signal inside and outside a detected polygon at different time intervals (Figs. 2 and 5). The categorization of the deformation rate is then determined by combining observations from each interferogram (Figure 5). Depending on the sensor technology, several classes of deformation rates can be defined. These categories are related to the time intervals at which a moving feature is detected by a coherent, respectively a decorrelated, signal. For instance, four categories are well defined with ERS data (Delaloye et al., 2007a): 'cm/day' refers to features detected on 1-day interferogram and decorrelated with larger time intervals, 'dm/month' to features not detected on 1-day interferograms and decorrelated on 35-day interferograms, ' $\mathrm{cm} / \mathrm{month}^{\prime}$ to features detected on 35-, 70- and 105-day interferograms and decorrelated for larger time intervals; and ' $\mathrm{cm} / \mathrm{year}^{\prime}$ to features detected only on 1-, 2- or 3-year interferograms (Figure 6).

DInSAR polygons are described by at least their spatial outline, the category of deformation rate, the typology of the related landform and, when necessary, some remarks. In most cases the typology of the related landform (geomorphologic process) can be identified on satellite or air-borne optical images or by field visits. As the confidence in a DInSAR polygon depends on the number of interferograms used for the detection and on the delimitation which is subjective and obviously might differ depending on the user, an index of reliability indicating the quality of the detection is also advised.

The compatibility between different sensors has also to be considered. The outline of the polygons can basically differ due to different ground resolution, incidence angle or acquisition mode. In comparison to ERS, recent very high-resolution X-band sensors such as TerraSAR-X (TSX) and COSMO-SkyMed (CSK) permit a better detection and delimitation of polygons. With a repeated cycle of 11 days or 1 day respectively it is, moreover, possible to parse the structure of the deformation rate categorization into more subtle subclasses (Figure 6).

\section{Evaluation of results}

When possible, inventoried DInSAR-detected movements must be compared with available field data. Pre-existing inventories of slope movements (landslide and/or rock glaciers), terrestrial geodetic survey data (DGPS, Total station, Lidar, etc.), as well as air-borne photogrammetry data are, for instance, precious sources of validation. In the absence of terrestrial data, only the analysis of several interferograms and a good knowledge of the corresponding geomorphology allow the signal to be interpreted as a movement and not attributed to noise or atmospheric artifacts. In any case, the interpretation of the dataset by a second user is highly recommended in order to improve the overall quality of the inventory. Finally, the use of a reliability index is really important for any third user of the inventory to know how accurate the detected polygon is. 

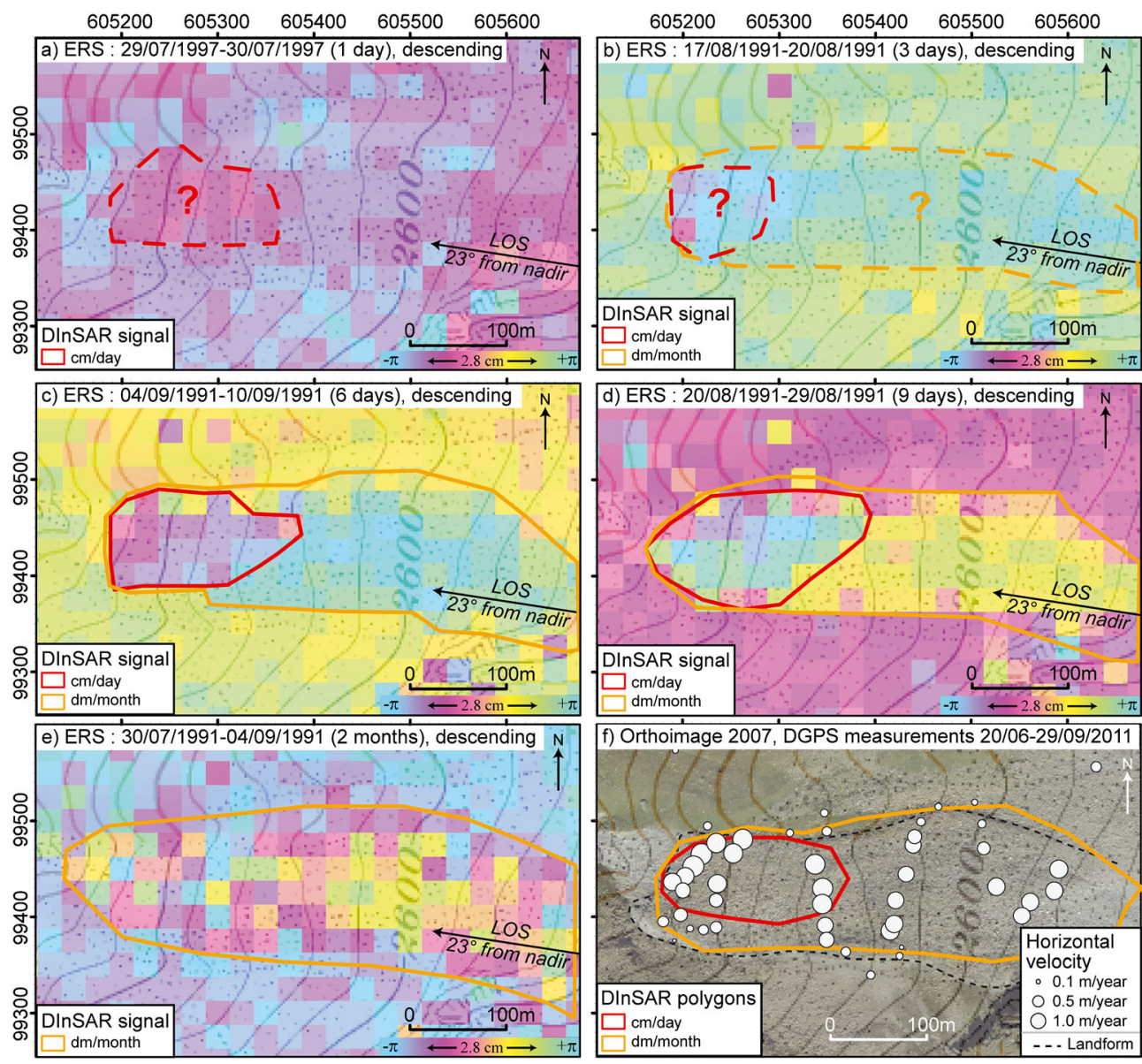

Figure 5. Detection of the Tsarmine rock glacier using ERS data. A large set of valid combinations of interferograms with different time intervals is required to increase the relevance of detected polygons. DGPS are used only to validate the order of velocity rate detected by DInSAR interpretation. (a) A small red signal could be detected on the 1-day interferogram. (b) Using a 3-day time interval, a signal could again be seen on the frontal part and around the whole landform. (c) The frontal part is now well detected on the 6-day interferogram whereas a signal appears around the rock glacier. (d) The frontal part becomes decorrelated on the 9-day interferogram. (e) The entire rock glacier is decorrelated on the 2-month interferogram. (a) Two DInSAR polygons have been drawn and classified in terms of the deformation rate as moving in the order of $\mathrm{cm} /$ day in red and of $\mathrm{dm} / \mathrm{month}$ in orange. The outline of the landform and measured DGPS points from summer 2011 are indicated.

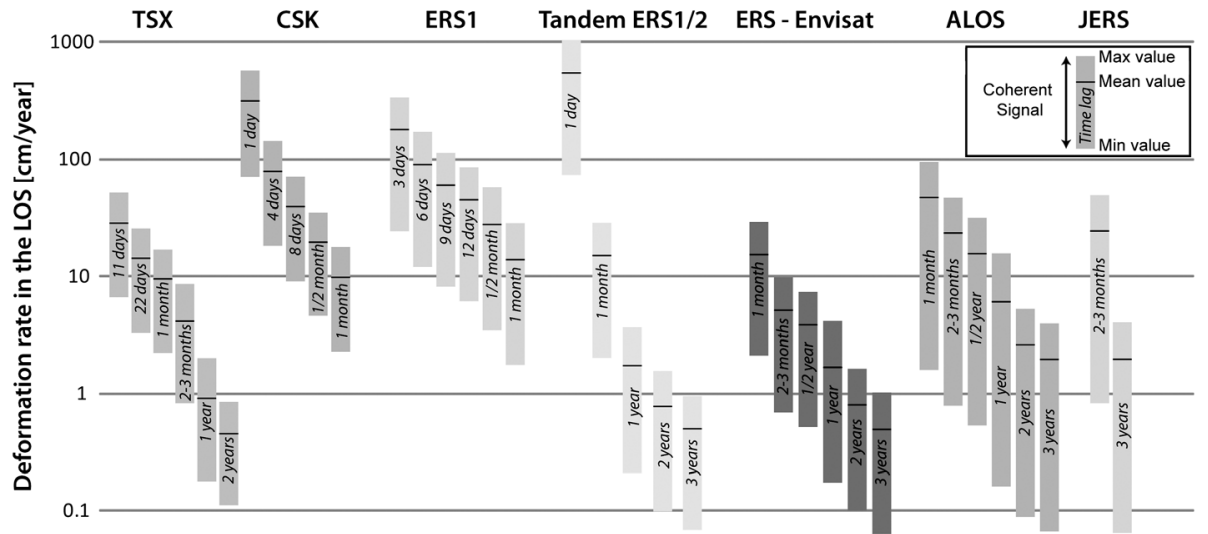

Figure 6. Deformation rate observed by SAR sensors for the most commonly used time interval. A bar defines the interval of deformation rate detected with a coherent signal on the interferogram of the selected time interval. For a specific time interval: a movement higher than the maximal value of deformation rate will be decorrelated on the interferogram, a movement lower than the minimal value is not detectable. The line in each bar defines the mean value of observable deformation rate.

\section{Application}

\section{Study area and data}

The methodology of DInSAR polygon inventory was applied at a regional scale on the periglacial belt of the Western Swiss
Alps $\left(46^{\circ} 4^{\prime} 0^{\prime \prime} \mathrm{N} / 7^{\circ} 36^{\prime} 0^{\prime \prime} \mathrm{E}\right)$ (Figure 7 ), here defined from the tree-line to the bottom of the glaciated area $(\sim 2300 \mathrm{~m}$ to $\sim 3000 \mathrm{~m}$ a.s.I.), on about $2650 \mathrm{~km}^{2}$; and was carried out over 3 months by at least two people using a large set of DInSAR data (Delaloye et al., 2007a, 2007b, 2008, 2010b; Lambiel et al., 2008). 


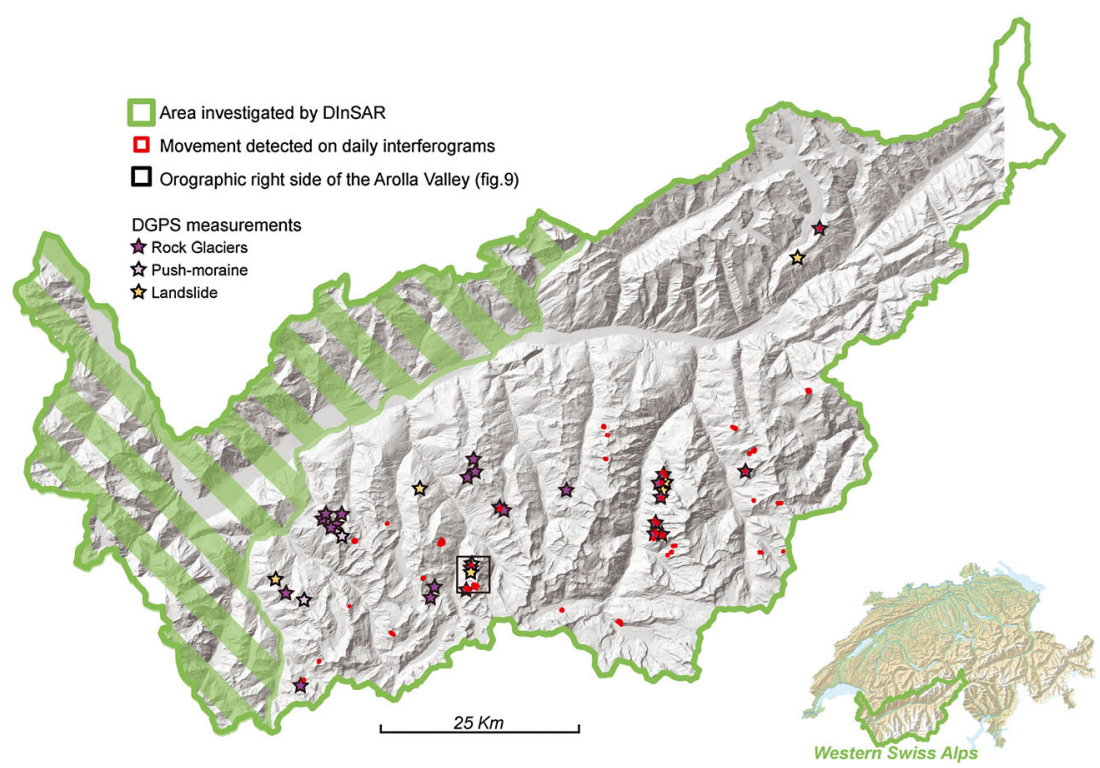

Figure 7. Area investigated by systematic mass wasting inventories based on DInSAR data. Stars represent study sites where DGPS measurements have been performed since 2006 and are significant sources of validation. Red outlines correspond to 42 DInSAR polygons detected on daily interferograms related to solifluction slopes, landslides, push-moraines as well as rock glaciers. The orographic side of the Arolla Valley detailed in Figure 9 is localized. This figure is available in colour online at wileyonlinelibrary.com/journal/espl

Sixty-three interferograms from the European ERS-1/2 and Japanese JERS satellites were used for the period 1993-2000, completed by some more recent acquisitions (2006-2007) from ENVISAT and ALOS PALSAR. DInSAR interferograms were processed in the 2-pass approach using the commercial software 'GAMMA' and a $25 \mathrm{~m}$ resolution digital elevation model (DEM) (DHM25 @ Swisstopo). Standard processing steps were applied and interferograms were multi-looked using a window $1 \times 5$ for ERS/Envisat, $2 \times 6$ for JERS and $2 \times 4$ for ALOS. An atmospheric phase model was applied and final interferograms have a $25 \mathrm{~m}$ posting.

DInSAR polygons were described by their location and geometry, the deformation rate according to four selected classes $(\mathrm{cm} /$ year, $\mathrm{cm} /$ month, $\mathrm{dm} /$ month and $\mathrm{cm} /$ day), the typology of the related landform and the reliability of the signal detection and interpretation.

\section{Examples of detected landforms}

In the region studied, DInSAR detected landforms are mainly related to debris-covered glaciers, rock glaciers, push-moraine, solifluction slopes as well as landslides

Debris-free glaciers have not been inventoried in our study. However, coherent fringe patterns can easily be observed on 1-day interferograms from the tandem ERS-1/2 in the wintertime. As reported by Weydahl (2001), heavily crevassed zones moving fast have a very low coherence and always display noisy DInSAR signals. Debris-covered glaciers are sometimes observed on 1-day interferograms in the wintertime, displaying a coherent signal pattern. The outline of debris-covered glaciers or large dead ice bodies is, however, better delimited at a daily or monthly time interval in the summertime (Figure 8 (a), (b)). A decorrelated signal is usually observed and caused in addition to the movement of the glacier by the exposure of the melting ice itself (thin debris coverage) and/or by the rapid settlement and movement of the glacier surface.

The velocity range of active rock glaciers is large, from some centimeters to several meters per year (Delaloye et al., 2008, 2010b; Lambiel et al., 2008). An obvious signal is detectable with the majority of the sensors for these active features
(Figure 6). For the most active ones, a signal may be already detected at a 1-day interval of tandem ERS-1/2 (Delaloye et al., 2008) (Figure 5(a), (b)) and decorrelation is widespread over the landform at a monthly interval on C-band interferograms (Figure 5(e)) and at all minimal time intervals on L- and X-band interferograms. For the slowest rock glaciers, any signal can be difficult to be evidenced at a monthly time interval but becomes evident, sometimes decorrelated at a yearly interval whatever the sensor (see Lambiel et al., 2008 for additional examples). However, as the signal noise increases significantly at the yearly time interval, low active, quasi-inactive rock glaciers may be difficult to detect.

Current push-moraines in the Alps are thick volumes of frozen debris that have been deformed by a glacier advance during the Little Ice Age. They could still contain superimposed debris-covered glacier ice on their internal side. Push-moraines are frequently affected by the back-creeping of still frozen sediments toward the former glacier talweg and/or by surface subsidence due to melting of massive ice (Delaloye, 2004). These processes imply the possible decorrelation of the area at a daily time interval in summer, rarely in winter, and a complete decorrelation on monthly interferograms (Figure 8(c), (d)).

On talus slopes or heavily weathered inclined regolith (here called debris mantle) solifluction processes may occur. They tend to form small lobes moving heterogeneously on the slope. The DInSAR signal tends generally to become progressively decorrelated especially on interferograms with a time interval larger than several months (Delaloye et al., 2007b). It is, however, possible to identify exceptionally daily signals on such slopes, which may be explained by the water impregnation of the ground surface rather than the terrain motion. In any case, the signal related to solifluction processes remains difficult to interpret and to distinguish from noise due to the small size of the single lobes and probably to the non-continuity of the movement during the summertime.

Finally, active deep-seated landslides of various sizes displaying deformation rates ranging from some millimeters to several decimeters per year have been detected. Whereas yearly intervals are the best suited to identify slowly moving landforms, rapid deformations can also be well detected on monthly interferograms (Figure 8(e), (f)). Some landslides are 

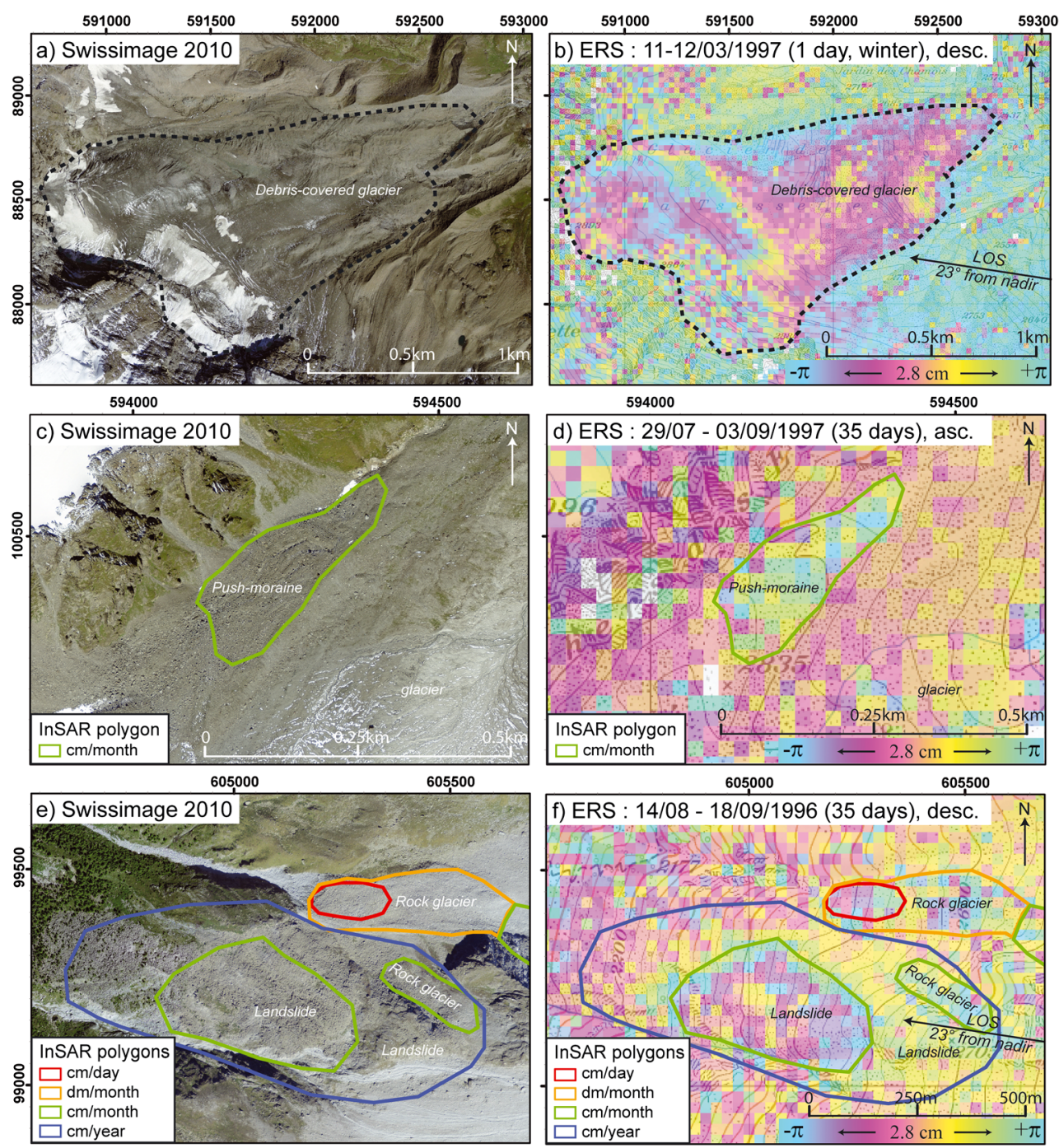

Figure 8. Orthoimages of (a) the debris-covered glacier of La Tsessette, (c) the push-moraine of Ecoulaies, and (g) the landslide of Perroc and their respective DInSAR signal on a 1-day interferogram (b) or on monthly interferograms (d) and (f). As debris-covered glaciers are not included in the inventory, no polygon is drawn in (a) and (b). DInSAR polygons were determined using a larger series of interferograms than the ones illustrated here (d) and $(\mathrm{f})$. Besides all the DInSAR polygons drawn in $\mathrm{c}$ to $\mathrm{f}$, the monthly interferograms allow only the detection of DInSAR polygons with $\mathrm{dm} / \mathrm{month}$ (signal decorrelated) and $\mathrm{cm} /$ month ((partly)-fringe pattern).

large (up to several $\mathrm{km}^{2}$ ) and may affect almost the whole of a mountain slope. Other active landforms like rock glaciers may be superimposed to the landslide area.

\section{Overview of the main results in western Swiss Alps}

The topography of the western Swiss Alps, mainly consisting of north-south oriented valleys, was optimal for an application of the DInSAR technique (Figure 7). A total of 1791 DInSAR polygons relating to about 1500 landforms were detected, with velocities ranging from about one centimeter to several meters per year (Table II).

The frequency of rapidly moving landforms was relatively high. Forty-two DInSAR polygons were detected on daily interferograms (Figure 7 and Table II), which correspond to a velocity higher than 1-2 $\mathrm{m} /$ year. These detected moving slopes concern two solifluction slopes, five landslides, nine pushmoraines and 26 rock glaciers. The inventory has especially contributed to the early detection of potentially hazardous active rock glaciers (Delaloye et al., 2010b). Most of the rock glaciers were then identified on monthly interferograms: 202

Table II. Frequency of inventoried DInSAR polygons related to mass wasting phenomena according to their typology and velocity. Debris-covered glaciers are not included. Some polygons can be related to the same landforms

\begin{tabular}{lcccrr}
\hline & \multicolumn{3}{c}{ Velocity of DInSAR Polygons } \\
\cline { 2 - 4 } Typology of InSAR polygons & $c m /$ day & $d m /$ month & cm/month & cm/year & Total \\
\hline Solifluction slope & 2 & 62 & 103 & 303 & 470 \\
Landslide & 5 & 16 & 87 & 197 & 305 \\
Push-moraine & 9 & 47 & 28 & 24 & 108 \\
Rock glacier & 26 & 202 & 329 & 351 & 908 \\
Total & 42 & 327 & 547 & 875 & $\mathbf{1 7 9 1}$ \\
\hline
\end{tabular}


were not detected on 1-day interferograms and decorrelated on 35-day interferograms ( $\mathrm{dm} / \mathrm{month}$ class), and 329 were detected on monthly interferograms and decorrelated for larger time intervals $(\mathrm{cm} / \mathrm{month}$ class). These two velocity classes contain most of the detected push-moraines too. Active landslides are usually detected on monthly interferograms $(\mathrm{cm} /$ month to $\mathrm{dm} /$ month classes), whereas the low active (sub-stable) ones, sometimes up to several squared kilometers wide, were evidenced only using annual time intervals $(\mathrm{cm} /$ year class). Several complex slope systems were also detected where landforms are juxtaposed, when not superimposed (Figs. 3 and 9).

The reliability of the results was evaluated by comparison with existing data such as rock glacier inventories (Delaloye and Morand, 1997; Morand, 2000; Lambiel and Reynard, 2003), DGPS measurements on more than twenty sites (Lambiel and Delaloye, 2004; Perruchoud and Delaloye, 2007; Delaloye et al., 2008) and some air-borne photogrammetry data. As illustrated in Figure 5 for the Tsarmine rock glacier, geodetic data displays deformation rates of the investigated landforms that were of the same order of magnitude as the one detected for the polygons by DInSAR analysis.

\section{Discussion}

\section{Dataset}

The required number of interferograms and time intervals depends on among others the displacement rate being observed and on the chosen sensor wavelength. When using for instance TSX data, a minimum of seven SAR images per year during the snow-free period should be acquired in each mode (ascending and descending modes) with at least two additional successive acquisitions the following year in order to construct a dataset permitting a complete analysis of slope movements. Such a kind of selection allows the detection of the whole range of movement rates to be performed, from a $\mathrm{cm} /$ year to $0.5-1.0 \mathrm{~m} /$ year with a set of interferograms having time intervals ranging from 11 days to 1 year. Larger displacement rates
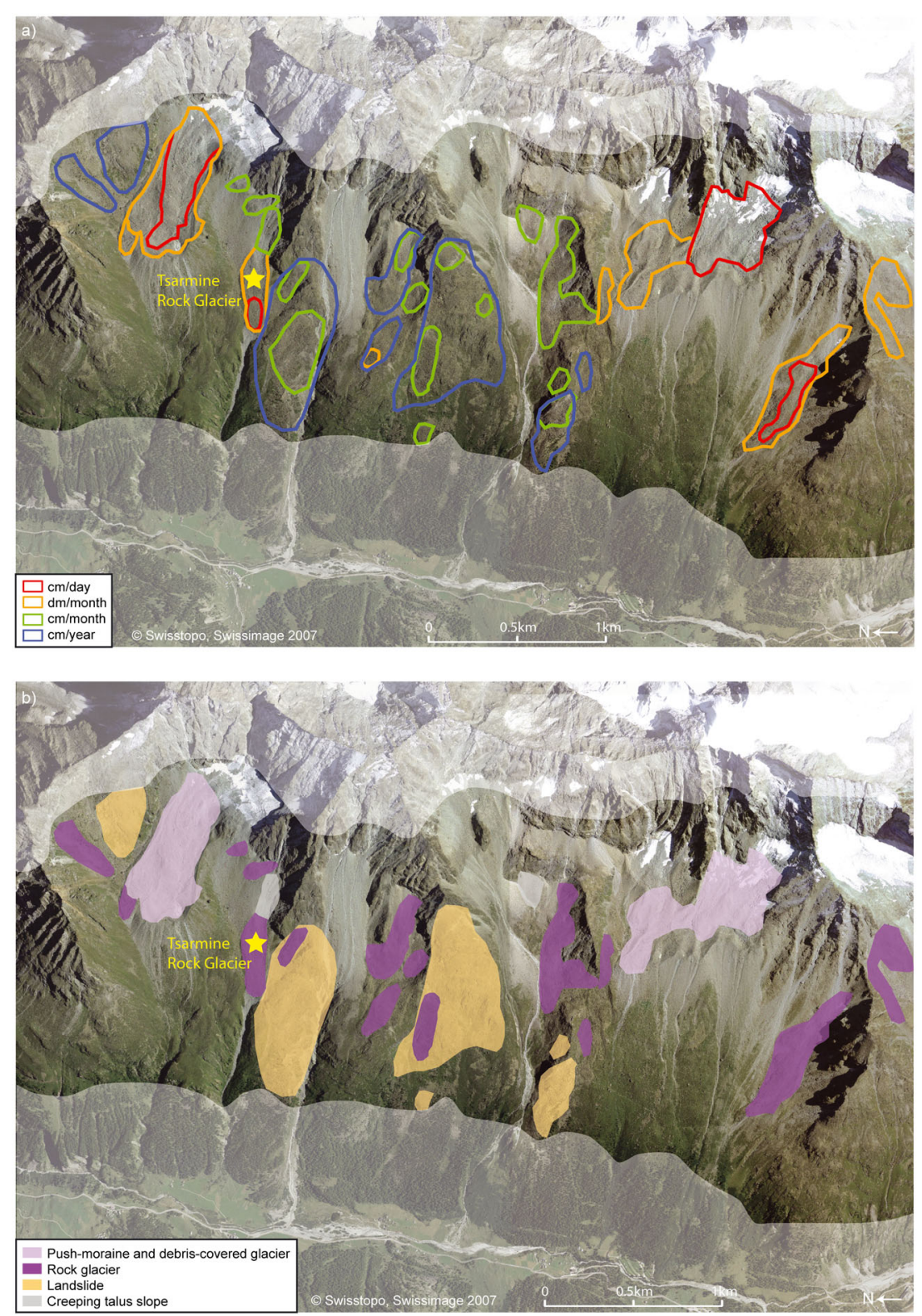

Figure 9. Moving landforms are often juxtaposed, when not superimposed and compose a 'complex slope systems', as illustrated by the orographic right side of the Arolla Valley, where moving features, including push-moraines, rock glaciers, landslides and saggings, are coalescent. (a) DInSAR detected moving zones, (b) Related landforms. The investigated area is limited due to layover, shadow and vegetation (transparent belt). 
could be detected - they will display decorrelated signals on 11-day interferograms - but cannot be precisely quantified.

Sixty-three ERS and JERS interferograms covering 9 years were available for this study and about half of them were finally only very partially used because of low quality. This dataset was large enough to allow a complete analysis of slope movement at the regional scale based on a wide range of time intervals. In any case, the larger the dataset and studied period are the more reliable the detection is. Planning the acquisition of a large dataset gives a safety margin in the analysis. It helps to avoid misinterpretations of the behavior of a landform during the selected studied time due to possible variations of the deformation rate or external events (rain, DEM error, atmosphere effects) and prevents technical problems, like a too-large spatial baseline, or the deletion of the acquisition order, sometimes making the analysis impossible.

\section{Quality of the inventory}

Even including a large number of landforms, the elaborated inventory is still incomplete and does not claim to be the ground truth. First, some DInSAR signals remain not well understood and appear to be rather related to the DInSAR processing than to any kind of slope movement or to field disturbance (vegetation, dew, etc.). In some cases, moreover, orthoimages were not good enough to confirm how accurate the detection is. Second, some areas could not be imaged due to layover and shadow effects (about $10 \%$ of the Western Swiss Alps using ascending and descending ERS). These invisible parts were mainly encountered in steep slope areas and around them due to propagation of layover and shadow effects. It also concerns the valley bottoms and the mountain crests. Whereas the former has mostly not been investigated (only parts above tree line have been mapped), the latter might have caused some gaps in the inventory. It means that mass wasting phenomena related to steep rock walls can usually not be detected. Finally, the $25 \mathrm{~m}$ resolution of ERS and JERS interferograms limits the detection of small targets. Moreover, the coherence and phase values are usually multi-looked during interferogram processing, which means that several interferometric cells are used to determine a single multi-looked interferometric cell. This averaging procedure is applied in order to obtain a less noisy interferogram with squared pixels, though the price to pay is a lower spatial resolution.

\section{On the use of the ERS archives and current acquisitions}

The ERS archive (with potentially 1-, 3-, 6- and 9-day time intervals) permits an insight to be gained of landforms moving faster than $1 \mathrm{~m} /$ year (up to $3-5 \mathrm{~m} /$ year), which is currently still not possible with TSX (11-day). This performance could certainly be approached with CSK using a short-term planning of 1 day; however it has not been investigated yet. Rock glaciers generally display strong inter-annual and seasonal velocity variations, with maximum values often reached in late summer or autumn (Perruchoud and Delaloye, 2007; Delaloye et al., 2010a; Noetzli, 2013; Wirz et al., 2014). Consequently, depending on what time an interferogram is available, the DInSAR-detected displacement rate may slightly differ from the average velocity. Moreover, the short repeat cycles and repeated acquisitions of current TSX or CSK acquisitions may be used to observe this seasonal kinematical behavior (Barboux et al., 2013a). Finally, the ERS archive permits the magnitude order of the deformation rates of many landforms two decades ago to be reconstructed, which may be useful in assessing the impact of ongoing climate change on periglacial slopes. An acceleration of the Aletschwald landslide could, for instance, be detected using Envisat data from 2006-2007 (Strozzi et al., 2007).

\section{Updating and upgrading an inventory}

Future investigations consist in updating inventories, that is, in identifying changes in the deformation rate, but also in upgrading them (identification of new polygons, improvement of the outlining of the polygons and finer quantification of the displacement rates) using recent or future data. Ongoing projects are investigating the possibilities for, so far as possible, automatically updating and upgrading the DInSAR polygons using new sensors like TSX (Barboux et al., 2013a, 2013b). However, by improving the spatio-temporal resolution capacity of detection, the spatio-temporal variability of the DInSAR polygons geometry increases too. Thus, evaluating the temporal changes in the behavior of active landforms on the basis of data inventoried from different sensor technologies may be a difficult task and will have to be performed carefully.

\section{Investigation around the world}

Other investigations applied in different mountain environments, like the Andes or the Himalayas, could improve the relevance and could show the adaptability of this technique whatever the location of the studied area. The automatic data storing and systematic acquisition of SAR data are ensured worldwide for most of the sensors - for very high resolution SAR satellites the data acquisition is performed only upon request, consequently only few areas are available with large archives - and allow the application of the methodology in other parts of the globe from data archives. However, current data accessibility is not always possible. It may be restricted by costs sometimes too high for scientific purposes and by availability. For instance, TSX successive stripmaps are acquired in the same orbit, making the availability of the two contiguous areas impossible at the same time. High quality DEM are not always available and the topography of the region could be not suitable for the application of DInSAR. However, this problem may be solved with the upcoming global DEM from the Tandem-X mission.

\section{Conclusion}

In this review, we show how DInSAR can be used: (1) to detect moving areas (DInSAR polygons) larger than $0.01 \mathrm{~km}^{2}$, occurring on several hundreds of active landforms and displacing faster than $0.01 \mathrm{~m} /$ year; (2) to delineate the outline of the polygons with an accuracy of $+/-25 \mathrm{~m}$; (3) to characterize their deformation rate into four categories; and (4) to assess for each polygon, sometimes juxtaposed and superimposed in composite slope systems, the related geomorphologic process causing their motion. This is clearly a revolutionary technique for short and long term studies of surface deformation in not only Alpine environments but also other mountainous regions.

The joint analysis of DInSAR data and orthophotos, and the verification of DInSAR-detected velocities with DGPS data have attested to the reliability of DInSAR for inventorying mass movements in remote areas. The construction of the inventory has permitted, in particular, to quantify for the first time the velocity of many landforms (rock glaciers, landslides) for which 
no data was available so far and to evidence potentially hazardous landforms like very rapid rock glaciers ( $>2-3$ m/year) using the former ERS 1-day and 3-day interferograms. Almost similar inventories could be drawn up in many other parts of the globe using current SAR sensors and some adaptations of the methodology.

Acknowledgements — The authors are grateful to Hugo Raetzo from the Swiss Federal Office for the Environment (FOEN), to Tazio Strozzi from Gamma Remote Sensing and to the European Space Agency (ESA) for their cooperation and for providing available SAR interferometry and airborne optical data related to the sample area. We also would like to express our thanks for the valuable comments of reviewers regarding the early version of this paper. Finally, we would like to thank every participant involved in the DGPS campaigns. ESA SAR: CP1.2338 (๔) ESA, processing Gamma Remote Sensing). TSX SAR: LAN 411 (@ DLR, processing Gamma Remote Sensing). DHM25 (c) 2003 Swisstopo. Swissimages and Pixel Map (c) 2010 Swisstopo.

\section{References}

Balzter H. 2001. Forest mapping and monitoring with interferometric synthetic aperture radar (InSAR). Progress in Physical Geography 25: 159-177. DOl:10.1177/030913330102500201

Bamler R, Hartl P. 1998. Synthetic aperture radar interferometry. Inverse Problems 14: R1-R54.

Barboux C, Delaloye R, Lambiel C, Strozzi T, Collet C, Raetzo H. 2013a. Surveying the activity of permafrost landforms in the Valais Alps with InSAR. In Mattertal - ein Tal in Bewegung. Publikation zur Jahrestagung der Schweizerischen Geomorphologischen Gesellschaft 29. Juni - 1 Juli 2011, St Niklaus. Graf C (ed): 7-19.

Barboux C, Delaloye R, Strozzi T, Lambiel C, Collet C. 2013b. TSX DInSAR data for detecting and monitoring slope motion phenomena in an Alpine periglacial environment at different resolution scales (Western Swiss Alps, Switzerland). TerraSAR-X Science Team Meeting, 10-12 June 2013, DLR Oberpfaffenhofen

Barrett BW, Dwyer E, Whelan P. 2009. Soil moisture retrieval from active spaceborne microwave observations: an evaluation of current techniques. Remote Sensing 1: 210-242. DOI:10.3390/rs1030210

Delacourt C, Allemand P, Berthier E, Raucoules D, Casson B, Grandjean P, Pambrun C, Varel E. 2007. Remote-sensing techniques for analysing landslide kinematics: a review. Bulletin de la Societe Geologique de France 178: 89-100.

Delaloye R, Morand S. 1997. Du Val Ferret au Grand-Combin (Alpes Valaisannes): Inventaire des glaciers rocheux et analyse spatiale du pergélisol à l'aide d'un système d'information géographique (IDRISI). Master Thesis. University of Fribourg, Switzerland

Delaloye R. 2004. Contribution à l'étude du pergélisol de montagne en zone marginale. PhD Thesis. Departement of Geosciences, Geography, University of Fribourg.

Delaloye R, Lambiel C, Lugon R, Raetzo H, Strozzi T. 2007a. ERS InSAR for detecting slope movement in a periglacial mountain environment (western Valais Alps, Switzerland). Proceeding of HMRSC-IX, Grazer Schriften der Geographie und Raumforschung 43: 113-120.

Delaloye R, Lambiel C, Lugon R, Raetzo H, Strozzi T. 2007b. Typical ERS InSAR signature of slope movement in a periglacial mountain environment (Swiss Alps). Proceeding of ENVISAT Symposium 2007 (ESA SP-636, July 2007).

Delaloye R, Strozzi T, Lambiel C, Perruchoud E, Raetzo H. 2008. Landslide-like development of rockglaciers detected with ERS 1-2 SAR interferometry. Proceding of FRINGE 2007 Workshop, 26-30 November (ESA SP-649, February 2008).

Delaloye R, Lambiel C, Gärtner-roer I. 2010a. Overview of rock glacier kinematics research in the Swiss Alps. Seasonal rhythm, interannual variations and trends over several decades. Geographica Helvetica 65: 135-145.

Delaloye R, Strozzi T, Lambiel C, Barboux C, Mari S, Stocker A, Techel F, Raetzo H. 2010b. The contribution of InSAR data to the early detection of hazardous active rock glaciers in mountain areas. Proceedings ESA Living Planet Symposium 2010, (ESA SP-686, December 2010).
Duro J, Albiol D, Mora O, Payas B. 2013. Application of advanced InSAR techniques for the measurement of vertical and horizontal ground motion in longwall minings. 13th Coal Operators' Conference, University of Wollongong, The Australasian Institute of Miningand Metallurgy \& Mine Managers Association of Australia: 99-106.

Echelard T, Krysiecki JM, Gay M, Schoeneich P. 2013. Détection des mouvements de glaciers rocheux dans les Alpes françaises par interférométrie radar différentielle (D-InSAR) dérivée des archives satellitaires ERS (European Remote Sensing). Geomorphology 3: 231-242.

Gabriel AK, Goldstein RM, Zebker HA. 1989. Mapping small elevation changes over large areas: differential radar interferometry. Journal of Geophysical Research 94: 9183-9191.

Hanssen RF. 2005. Satellite radar interferometry for deformation monitoring: a priori assessment of feasibility and accuracy. International Journal of Applied Earth Observation and Geoinformation 6: 253-260. DOI: 10.1016/j.jag.2004.10.004.

Jones H, Vaughan RA. 2010. Remote Sensing of Vegetation: Principles, Techniques, and Applications. Oxford University Press: Oxford.

Klees R, Massonnet D. 1999. Deformation measurements using SAR interferometry: potential and limitations. Geologie en Mijnbouw 77: 161-176.

Lambiel C, Reynard E. 2003. Cartographie de la distribution du pergélisol et datation des glaciers rocheux dans la région du Mont Gelé (Valais). Physische Geographie 41, Geographisches Institut der Universität Zürich: 91-104.

Lambiel C, Delaloye R. 2004. Contribution of real-time kinematic GPS in the study of creeping mountain permafrost: examples from the Western Swiss Alps. Permafrost and Periglacial Processes 15: 229-241. DOI: 10.1002/ppp.496.

Lambiel C, Delaloye R, Strozzi T, Lugon R, Raetzo H. 2008. ERS InSAR for assessing rock glacier activity. 9th International Conference on Permafrost 29 June-03 July 2008: 1019-1025.

Lilleøren KS, Etzelmüller B, Gärtner-Roer I, Kääb A, Westermann S, Guðmundsson Á. 2013. The distribution, thermal characteristics and dynamics of permafrost in Tröllaskagi, northern Iceland, as inferred from the distribution of rock glaciers and ice-cored moraines. Permafrost and Periglacial Processes 24: 322-335. DOl:10.1002/ ppp.1792.

Liu L, Millar Cl, Westfall RD, Zebker Ha. 2013. Surface motion of active rock glaciers in the Sierra Nevada, California, USA: inventory and a case study using InSAR. The Cryosphere Discussions 7: 343-371. DOI: 10.5194/tcd-7-343-2013.

Massonnet D, Feigl KL. 1998. Radar interferometry and its application to changes in the earth's surface. Reviews of Geophysics 36: 441.

Morand S. 2000. Inventaire des glaciers rocheux du Val d'Arolla. Rapport interne. Service des forêts et du paysage du Canton du Valais, Sion.

Nagler T, Mayer C, Rott H. 2001. Feasibility of DInSAR for mapping complex motion fields of Alpine ice- and rock-glaciers. Proceedings of the Third International Symposium on Retrieval of Bio- and Geophysical Parameters from SAR Data for Land Applications, 11-14 September 2001 (ESA SP-475, 2002): 377-382.

Nagler T, Rott H, Kamelger A. 2002. Analysis of landslides in alpine areas by means of SAR interferometry. Proceedings of IGARSS 2002, June 24-28: 198-200.

Noetzli J (ed). 2013. PERMOS 2013. Permafrost in Switzerland 2008/ 2009 and 2009/2010. Glaciological Report Permafrost No. 10/11 of the Cryospheric Commission of the Swiss Academy of Sciences, 80.

Nolan M, Fatland DR. 2003. Penetration depth as a DInSAR observable and proxy for soil moisture. IEEE Transactions on Geoscience and Remote Sensing 41: 532-537. DOI: 10.1109/TGRS.2003.809931.

Perruchoud E, Delaloye R. 2007. Short-term changes in surface velocities on the Becs-de-Bosson rock glacier (western Swiss Alps). Proceedings of the 9th International Symposium on High Mountain Remote Sensing and Cartography, 2007, 248 S 2004: 131-136.

Rosen Pa, Hensley S, Joughin IR, Li FK, Madsen SN, Rodriguez E, Goldstein RM. 2000. Synthetic aperture radar interferometry. Proceedings of the IEEE 88: 333-382.

Rott H, Scheuchl B, Siegel A, Grasemann B. 1999. Monitoring very slope movements by means of SAR interferometry: a case study from a mass waste above a reservoir in the Ötztal Alps, Austria. Geophysical Research Letters 26: 1629-1632. 
Rott H, Nagler T, Rocca F, Prati C, Mazzotti A, Keusen H, Liener S, Tarchi D. 2003. InSAR techniques and applications for monitoring landslides and subsidence. In book: Geoinformation for European-wide Integration, Benes (ed). MillPress: Rotterdam; 25-31.

Smith LC. 2002. Emerging applications of interferometric synthetic aperture radar (InSAR) in geomorphology and hydrology. Annals of the Association of American Geographers 92: 385-398.

Strozzi T, Wegmuller U, Matzler C. 1999. Mapping wet snow covers with SAR interferometry. International Journal of Remote Sensing 20: 2397-2403.

Strozzi T, Wegmuller U, Werner C, Wiesmann A. 2002. Alpine landslide periodical survey. Proceeding of IGARSS 2002 6: 3629-3631. DOI: 10.1109/IGARSS.2002.1027272.

Strozzi T, Kääb A, Frauenfelder R. 2004. Detecting and quantifying mountain permafrost creep from in situ inventory, space-borne radar interferometry and airborne digital photogrammetry. International Journal of Remote Sensing 25: 2919-2931.

Strozzi T, Farina P, Corsini A, Ambrosi C, Thüring M, Zilger J, Wiesmann A, Wegmüller $U$, Werner C. 2005. Survey and monitoring of landslide displacements by means of L-band satellite SAR interferometry. Landslides 2: 193-201.

Strozzi T, Wegmüller U, Perruchoud E, Delaloye R, Kääb A, Ambrosi C. 2007. Evolution of a deep-seated rock mass movement observed with satellite SAR interferometry. Proceeding of the FRINGE 2007 Workshop, 26-30 November, Frascati, Italy (ESA SP-649, February 2008).
Tarayre H, Massonnet D. 1996. Atmospheric propagation heterogeneities revealed by ERS-1 interferometry. Geophysical Research Letters 23: 989-992.

Ulaby FT, Dobson MC, Bradley Ga. 1981. Radar reflectivity of bare and vegetation-covered soil. Advances in Space Research 1: 91-104. DOI: 10.1016/0273-1177(81)90384-7.

Walter D, Busch W. 2012. Influence of DEM quality parameters on the topographic phase correction in DInSAR. Proceedings of IGARSS 2012: 3927-3930.

Wegmüller U, Strozzi T. 1998. Characterization of differential interferometry approaches. Proceedings of EUSAR '98, 25-27 May 1998.

Weydahl DJ. 2001. Analysis of ERS tandem SAR coherence from glaciers, valleys, and fjord ice on Svalbard. IEEE Transactions on Geoscience and Remote Sensing 39: 2029-2039. DOI: 10.1109/36.951093.

Williams S, Bock Y, Fang P. 1998. Integrated satellite interferometry: tropospheric noise, GPS estimates and implications for interferometric synthetic aperture radar products. Journal of Geophysical Research 103: 27051-27067.

Wirz V, Geertsema M, Gruber S, Purves RS. 2014. Temporal variability of diverse mountain permafrost slope movements derived from multiyear daily GPS data. Landslides (in press).

Zebker A, Rosen PA, Hensley S. 1997. Atmospheric effects in interferometric synthetic aperture radar surface deformation and topographic maps. Journal of Geophysical Research 102: 7547-7563.

Zhang T, Zeng Q, Li Y, Xiang Y. 2008. Study on the relation between InSAR Coherence and Soil Moisture. The International Archives of the Photogrammetry, Remote Sensing and Spatial Information Sciences 37: 131-134. 